\title{
Arm Cycle Ergometer Electro-Mechanical System Design For Post-Stroke Medical Rehabilitation
}

\author{
Yosua Hendra Kristanto ${ }^{1, a)}$, Welina Ratnayanti Kawitana ${ }^{1}$, Tri Anggono Prijo ${ }^{1}$ \\ ${ }^{1}$ Department of Physics, Faculty of Science and Technology, Universitas Airlangga, Surabaya 60115, Indonesia \\ a) Corresponding author: hendra04yosua @ gmail.com
}

\author{
Article History \\ Received : 01 April 2021, Revised : 15 April 2021, Accepted : 23 April 2021, Online : June 2021
}

\begin{abstract}
This study was done to make the electro-mechanical arm ergometer cycle system used as post-stroke patient physiotherapy. The management system was expected to set the rotary frequency according to the therapeutic needs. To set the frequency of the rotation, the PID control with rotation sensor was used as feedback. The rotating sensor used consisted of the optocoupler and a rotary encoder. Based on the research that has been done, obtained constants of $K p=$ $0055, K i$ and $K d=2545=0.00005$. Constants were selected because they were the most optimum constant trial and error method. The system is made to have a more significant percentage of error of 5\%. In this study, the response time values obtained for each additional mass of the load at each frequency setting result are increased.
\end{abstract}

\section{INTRODUCTION}

The way to minimize disability after a stroke is through rehabilitation [10]. The duration of rehabilitation needed for stroke patients varies depending on the type of stroke suffered. On average, patients were hospitalized in a stroke rehabilitation unit for 16 days, followed by outpatient treatment for several weeks. Although most of the improvement occurs in the above time, the brain will continue to learn about motor skills throughout life [2]. So the exercises that are done during rehabilitation can help reduce the level of disability in post-stroke organs.

One of the rehabilitation of post-stroke patients is exercise therapy (physiotherapy) carried out by physiotherapists. The increase in exercise intensity is proportional to the improvement in quality of life. Research Kwakkel et al. (2004), a meta-analysis, showed that increasing the intensity of exercise therapy time, especially if it was added to at least 16 hours in the first six months, had a small but significant effect on the functional ability of stroke survivors. In order to make the performance of physiotherapists lighter and improve the quality of medical rehabilitation services, through this research, an electro-mechanical system for post-stroke medical rehabilitation will be established. This system is used to guide the patient in doing circular motion exercises on the arm following the training pattern required

needed automatically, especially upper limb exercises, namely the hands. The muscles in the arms trained in this exercise are the biceps (flexor), triceps (extensor), brachioradialis, and flexor digitorum superficialis muscles. The system that will realize based on a microcontroller, where the control of the motor to be regulated is the controlled rotational speed and time. The rotation speed and time settings can be adjusted to the patient's condition and the target of the results of the exercise aimed at post-stroke patients. This design's results are expected to assist the work of nurses with reliable accuracy and precision of movement and at a more affordable price so that patients can have them so that patients do not need to go to the hospital often.

Rotary speed conditioned to the patient's needs can be adjusted based on the pulse width (PWM) on the microcontroller. In general, the average everyday person's hand can complete 50 rounds in one minute [13]. For time variations, a timer is used on the microcontroller so that the nurse can set the exercise time performed by the patient according to the status of the patient undergoing the training process. 


\section{MATERIALS AND METHODS}

The design of the system that will be made in the study is to automate hand muscle movement exercises in motion exercises resembling the motion of pedaling a bicycle. The electro-mechanical system design that will be made is designed so that the rotational frequency and exercise time can be adjusted according to the needs of therapy by the physiotherapist. The system that will be used to adjust the rotational frequency of the motor consists of a gear set, an electric motor, and an optocoupler system. This gear set is used to adjust the motor's torque to swing the pedal arm still even though the pedal mass is significant.

Adjusting the motor's rotational frequency can be done by adjusting the PWM generated by the microcontroller. PWM generated by this microcontroller can be done using the timer port that is already available on the microcontroller. PWM will be active when the start button is pressed, which means the motor will rotate. Meanwhile, an optocoupler sensor is used to read the rotational frequency of the motor. This rotary encoder is mounted on the motor shaft so that the rotation of the motor is equal to the rotation of the rotary encoder so that the rotational frequency of the motor can be known from the number of pulses generated divided by the number of gaps in the rotary encoder, if the rotational frequency of the motor is smaller than the set frequency then the PWM will increase.

In comparison, if the rotational frequency of the motor is greater than the set frequency, the PWM will decrease. The timer in this system will be activated when the motor's rotational frequency follows the set frequency, and to generate the timer in this system is done by the microcontroller. Setting the timer on the microcontroller can be done by using one of the timer ports that are already available on the microcontroller. The setting frequency, setting time, and motor rotational frequency will be displayed on the LCD screen. The block diagram of the overall system design can be seen in Figure 1.

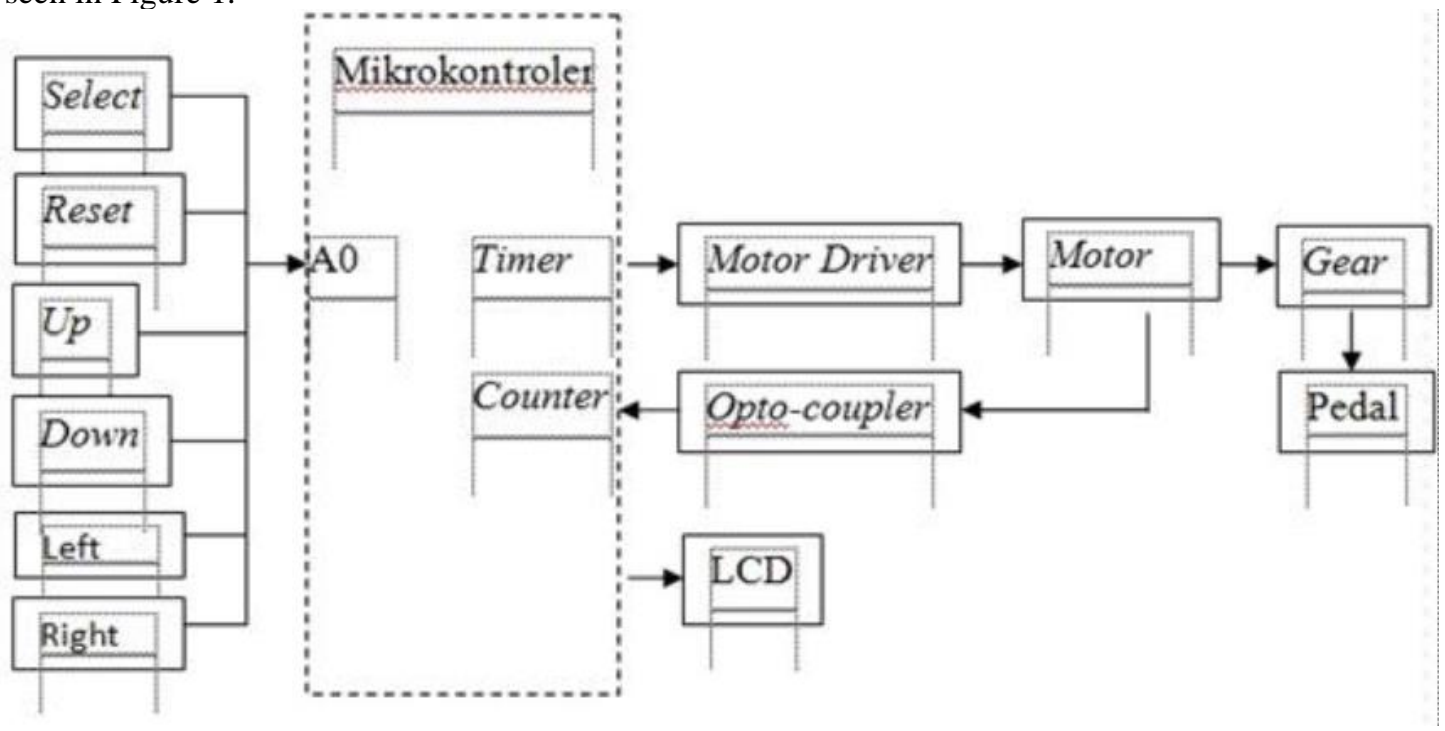

FIGURE 1. System Hardware Design Block Diagram.

In this study, one of the uses of control variables that can affect the system is adding the mass of the load given to the pedal. The disturbance indirectly affects the rotary frequency control system. Therefore, for processing at the sum junction, the initialization of the error conveyed is very important, where the process is called feedback control. In general, the control system diagram as a whole can be seen in Figure 2.

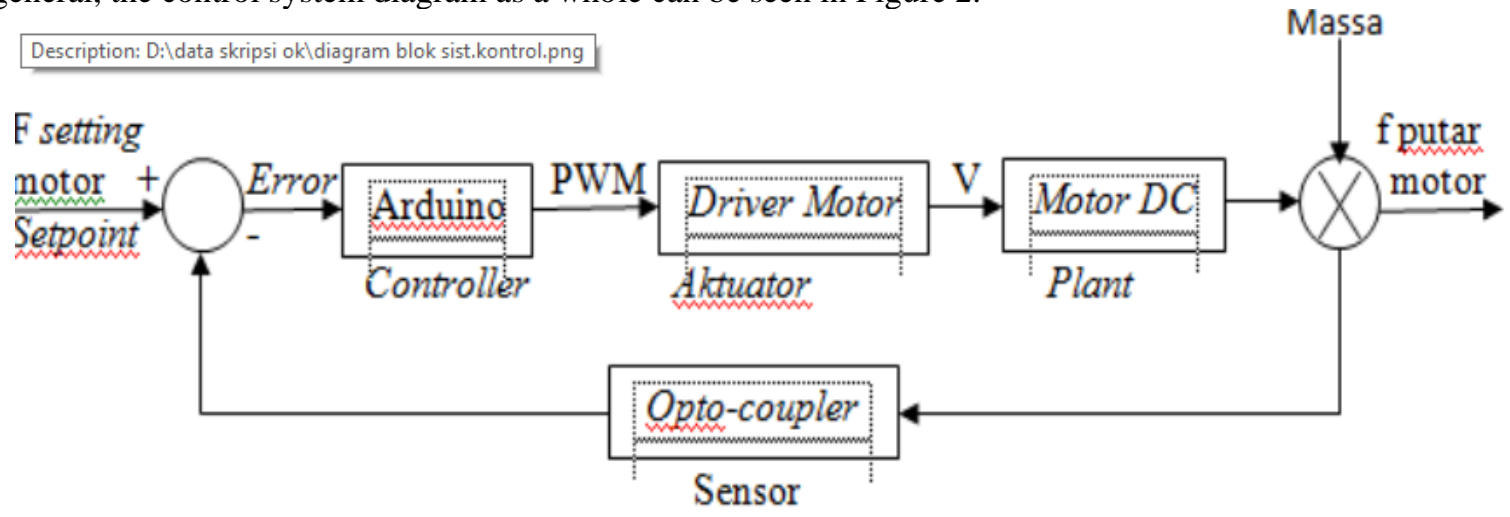

FIGURE 2. Control System Diagram 


\section{Tool Embodiment Stage}

This stage begins with making a mechanical construction, then designing a circuit (layout) of essential components, namely the microcontroller circuit system integrated with the optocoupler sensor system, motor driver, DC motor, and LCD. The rotational speed of the motor in this electro-mechanical system will be divided into three levels. The first level has a rotational speed of $50 \mathrm{rpm}$ for the first stage of patient therapy, the second level has a rotational speed of $75 \mathrm{rpm}$ for the second stage of patient therapy, and the third level has a rotational speed $100 \mathrm{rpm}$ for the third stage of patient therapy.

\section{System Mechanical Construction}

The initial stage in this research is to make a mechanical construction of the system. The mechanical construction made is designed so that the system can still run when there is a change in the mass of the hand. The system consists of a DC motor, optical rotary encoder, optocoupler, and gear banding for the system to work as desired. The DC motor must be connected to the gear first before it comes into contact with the mass. This gear is adjusted to the torque and rotational frequency you want to achieve and adjust the composition of the gear banding. The mechanical design of the system will be shown in Figure 3.

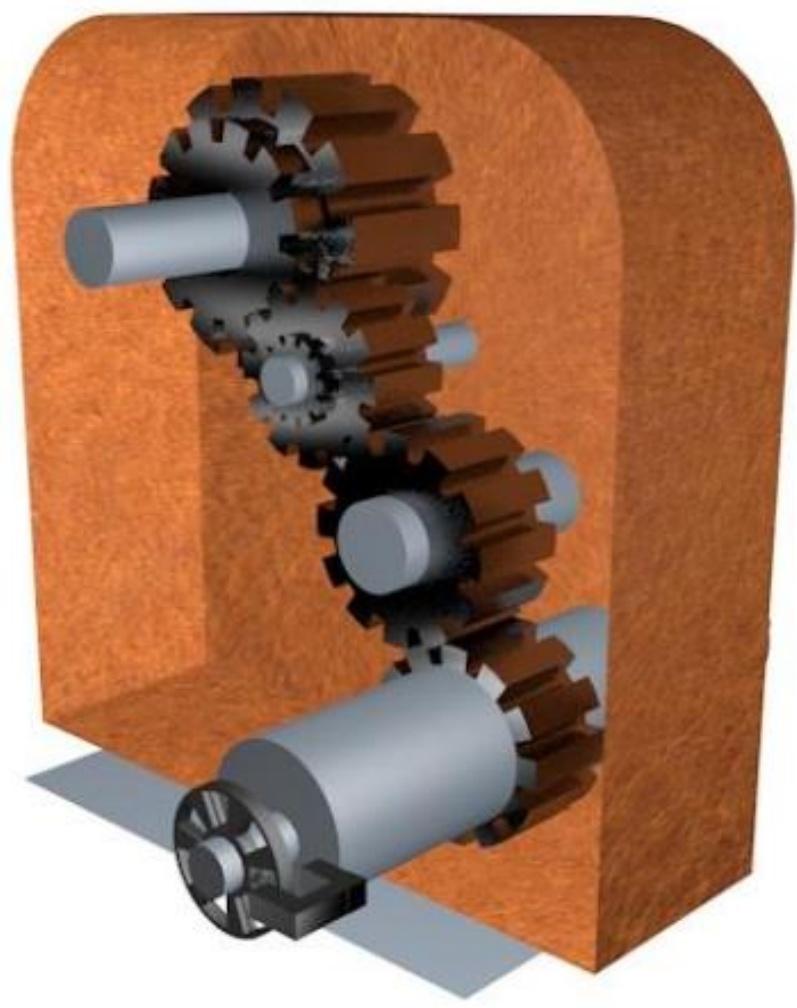

FIGURE 3. Electromyography (EMG) Design

\section{Hardware Design}

The hardware made in this study is a physiotherapy tool for post-stroke patients, especially for microcontrollerbased hand muscle movement exercises that can be adjusted for rotation frequency and therapy time. The hardware in this study consists of a light sensor circuit, a motor driver circuit, an LCD interface circuit, and an Arduino UNO kit.

\section{Opto-Coupler Circuit}

The reading of changes in the motor's rotational speed is carried out by installing an optocoupler and an optical rotary encoder. The light sensor in the optocoupler is a photo-transistor sensor, and the infrared LED is the light source. The following will explain the principle of the optocoupler sensor 
Vout $=$ Vcc $-I L R L$

$I L=\beta I b$

$R L=100 \mathrm{~K} \Omega, R D=390 \Omega, I b$ is the current flowing through the photo-transistor base; $\mathrm{I}_{\mathrm{L}}$ is the current flowing through the photo-transistor collector.

When $\mathrm{Ib}=0$ (dark state), then IL $=0$ so that Vout $=$ Vcc (High condition) When $\mathrm{Ib}=\max$ (light state), then IL $=\max$ so Vout $=0$ (Low condition) On photo-transistor Ib Intensity. So it can be written $\mathrm{Ib}=($ Intensity) $\mathrm{x} \mathrm{K}$, where $\mathrm{K}$ is a constant. So $\mathrm{I}_{\mathrm{L}}=\beta \times \mathrm{K} \times$ Intensity. By using this equation, we can determine the relationship between light intensity and output voltage. So to increase the sensitivity of the sensor can be done by increasing the value of $R_{L}$. The pulse to be processed by the microcontroller should be in a high or low condition. The sensor circuit is given a NOT gate. This NOT gate functions as a digital comparator because the NOT gate's output voltage is only 0 or 5

\section{Motor Driver Circuit}

The microcontroller can be used to control DC motors. However, the microcontroller is a device that works in the Transistor-Transistor Logic (TTL), which has a voltage range of 0 volts to 5 volts. The I/O port (Input/Output) of the microcontroller only provides a current of $20 \mathrm{~mA}$, so if you want to use a microcontroller to control devices that require larger currents, a driver circuit is needed (Heryanto and Adi, 2008). One device that requires large current consumption is a DC motor. The driver circuit is a current or voltage amplifier circuit consisting of transistors. In electronic circuits, transistors amplify signals, meaning that weak signals at the input are converted into solid signals at the output (Sutrisno, 1986). In this case, the weak input signal comes from the microcontroller, and the strong output signal comes from the power supply directly. The primary circuit of the motor driver is shown in Figure 4.

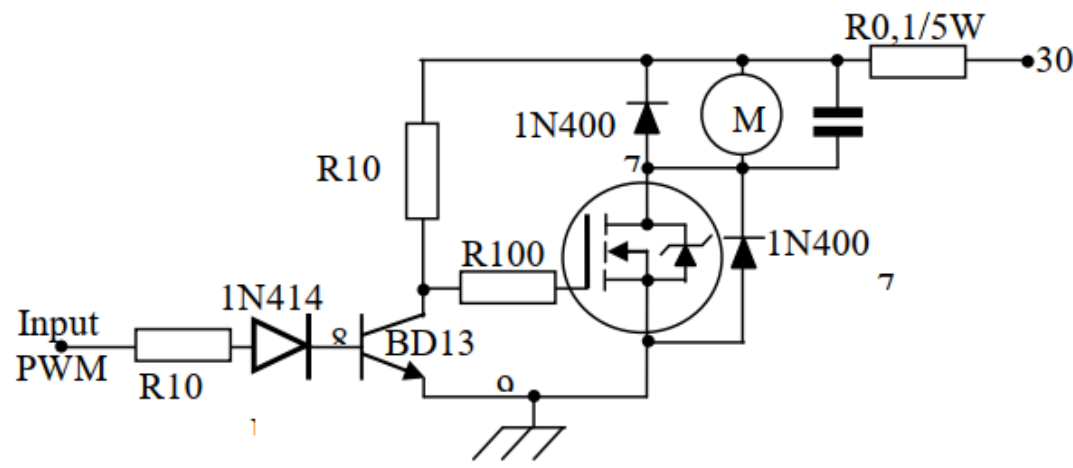

FIGURE 4. Motor Driver Circuit Schematic.

\section{LCD circuit}

The LCD used in this study is a dot-matrix LCD with $2 \times 16$ characters, which has 16 pins. This LCD circuit is equipped with a 1N4002 diode; the LCD datasheet itself adjusts the installation of this diode. At the same time, the installation of a variable resistor is used to adjust the contrast on the dot matrix LCD. The use of LCD in this study displays the amount of PWM generated, the motor rotational frequency, and the time value.

\section{Arduino UNO circuit}

In this study, Arduino UNO is used as a frequency meter, PWM generator and displays data to the LCD. R10

\section{Test Preparation Stage}

It is necessary to make a tool that can move like the movement that can be done by the hand muscles, especially the movement of pedaling a bicycle. This simulation tool for hand muscle movement is needed considering the system testing with variations in the mass of the load to be carried out. This behavior is because testing with a point mass will be heavier than the mass arranged to resemble the muscles in hand. In this study, the hand muscle simulation tool has the same arm length, $50 \mathrm{~cm}$, and has a total weight of $3 \mathrm{~kg}$. The total mass of the pedal used is $1 \mathrm{Kg}$. Variations that will be carried out in system testing are systems that are run without a load, systems that are run by increasing the pedal load, systems that are run by installing a hand muscle simulation tool on the pedal and then adding an iron plate as the mass of the load mounted on the arm with a total mass of $4 \mathrm{Kg}$ and $6 \mathrm{Kg}$. 


\section{Testing the Kp, Ki, and Kd Values of the System}

In the research, the system used to control the rotational frequency of the motor is the PID control system. The system runs according to predetermined proportional, integral, and derivative constants. These constants were obtained by trial and error method and studied from references on the internet. Determination of the constant value of the PID control system that needs to be considered is the influence of each constant. The system's parameters are seen from the rise time, overshoot, settling time, steady state error, and stability.

In the test of the determined constant, it is carried out using a motor with no load and with a pedal weighing 1 $\mathrm{kg}$. The two variations of the data are expected to compare the errors of the formed control system.

\section{Measurement of Pedal Rotation Frequency against Mass Load and PWM Value}

The rotary encoder used in this study has 20 slots, so to calculate the rotational frequency of the motor, the number of pulses calculated must be divided by 20 .

$$
\text { Rotational Frequency }=\frac{(\text { The number of pulse } x 60) / 20}{7}
$$

The value of 60 is used to change to RPM units. The value of 20 is the number of pulses in the rotary encoder used. The value of 7 is obtained from the gear ratio. The gear ratio used is $7: 1$, which means seven motor rotations equals one revolution of the pedal. Variations in the mass of the load that will be carried out to test the system are a system that is run without a load, a system that is run by increasing the pedal load, a system that is run by installing a hand muscle simulation tool on the pedal and then adding a load mass mounted on the arm with a total mass of $4 \mathrm{Kg}$ and $6 \mathrm{Kg}$.

\section{System Response Time Measurement}

System response time is the fastest processing time required by control to reach the set value. The ability of a system to reach this (stable) setting will be challenging to achieve. Therefore, the system response time is considered to have been reached when the resulting error is less than $13 \%$. To find out the system response time, you can This is done by looking at the time it takes to reach the rotating frequency setting on each variation of the mass of the load with an error of less than $13 \%$.

\section{RESULTS AND DISCUSSIONS}

\section{Results of Hardware Assemblies (Hardware)}

The hardware made in this research consists of a series of motor driver circuits, light sensors, and LCD interface circuits. Each hardware device made in this study must be tested for its function to work correctly.

\section{Motor Driver Assemblies}

A motor driver circuit was used as an electronic switch to drive the motor according to the PWM generated by the microcontroller. The motor driver made in this study is a motor driver who can only move the motor in one direction of movement. This motor driver uses NPN transistors and n-channel MOSFETs. The transistors used in this study are the BD139 transistor and the IRFP460 MOSFET. The BD139 transistor is designed so that the voltage entering Vgs MOSFET IRFP460 meets the voltage value according to the datasheet. The 10K resistor installed before the BD139 transistor functions so that the electrical current issued by the microcontroller is small so it does not damage the microcontroller. IN4007 diodes are connected in parallel to the drain and source, which serves to protect the MOSFET. In contrast, the other IN4007 diode in the motor driver circuit is used as a safeguard against large transient currents generated by the motor, especially when the motor is about to move. 1N4148 diode is installed in the initial circuit of the motor driver to ensure that no transient current enters the microcontroller. 


\section{Opto-Coupler Assemblies}

Based on the results of the tests that have been carried out, the results obtained when the optocoupler is blocked (dark state), the resulting voltage level is 5 volts (high), and when it is not blocked (light conditions), the resulting voltage level is 0 volts (low), will but because after the sensor circuit is given a NOT gate, the output voltage is the opposite. The optocoupler output signal, when played with $100 \%$ PWM, produces a frequency of 1,230 RPM. Besides that, the resulting signal forms a square signal indicating that the light sensor circuit has been functioning correctly.

\section{LCD Assembly Results}

Based on the results of the tests that have been carried out, it can be seen that the circuit that has been made can function adequately. This result is indicated by the LCD layer, which can display data as desired.

\section{System Response Time Measurement}

After designing the mechanical and hardware systems, the next step is programming, aiming to create a rotary frequency control system. The rotary frequency control system in this study uses a PID control system. This PID control system is necessary to determine the constants $\mathrm{Kp}, \mathrm{Ki}$, and $\mathrm{Kd}$. In this study, the step used to determine these constants uses the trial and error method. For this reason, while determining the PID constant, the motor is carried out with the motor without pedals. The value of the PID constant used in this study is the Kp constant of 0.055 , the Ki constant of 2.545 , and the Kd constant of 0.00005 . The PID constants were chosen because they produce a motor rotational frequency that matches the set frequency.

In this motor rotational frequency regulation system, changes in the value of the motor rotational frequency are affected by changes in the PWM value. The PWM value will increase until the rotating frequency reaches the setting rotating frequency value. The change in the PWM value is determined by the determination of the $\mathrm{Kp}, \mathrm{Ki}$, and $\mathrm{Kd}$ constants. The measurement of the frequency value (PWM) is measured against time at each setting frequency value and the value of $\mathrm{Kp}, \mathrm{Ki}$, and $\mathrm{Kd}$. The result was shown in Table 1.

TABLE 1.. The measurement of the frequency value (PWM)

\begin{tabular}{ccccc}
\hline $\begin{array}{c}\text { Mass } \\
(\text { Kg })\end{array}$ & $\begin{array}{c}\text { Set Frequency } \\
(\text { PWM })\end{array}$ & $\begin{array}{c}\text { Real Frequency } \\
(\text { PWM })\end{array}$ & $\Delta \mathbf{f}$ & Error $(\%)$ \\
\hline 0 & 100 & 102.17 & 11.351 & 11.12 \\
\hline & 75 & 74.45 & 6.97 & 9.36 \\
\hline & 50 & 50.5 & 5.65 & 11.01 \\
\hline 1 & 100 & 100.29 & 5.89 & 5.873 \\
\hline & 75 & 75.73 & 6.01 & 7.94 \\
\hline 4 & 50 & 51.63 & 6.577 & 12.74 \\
\hline & 100 & 104.629 & 11.53 & 11.02 \\
\hline & 85 & 82.483 & 7.22 & 7.754 \\
\hline 6 & 70 & 75.084 & 9.39 & 12.5 \\
\hline & 100 & 107.28 & 10.13 & 9.443 \\
\hline & 85 & 82.628 & 9.557 & 11.57 \\
\hline & 70 & 74.229 & 8.801 & 11.85 \\
\hline
\end{tabular}

Based on the data analysis that has been carried out, the \% error $>5$ indicates that the selected $\mathrm{Kp}, \mathrm{Ki}$, and $\mathrm{Kd}$ values are not under the expectations of system control stability.

\section{Testing Motor Rotation Frequency Using Variation of Load Mass}

Device evaluation using a different load mass at each rotational frequency to prove that the system made can adjust the rotational frequency with variations in the load mass. The variation of the load mass on the pedal when the system is working can affect the rotation frequency-moreover, the PWM value generated by the motor. The average PWM values are shown in Figures 5, 6, and 7. 


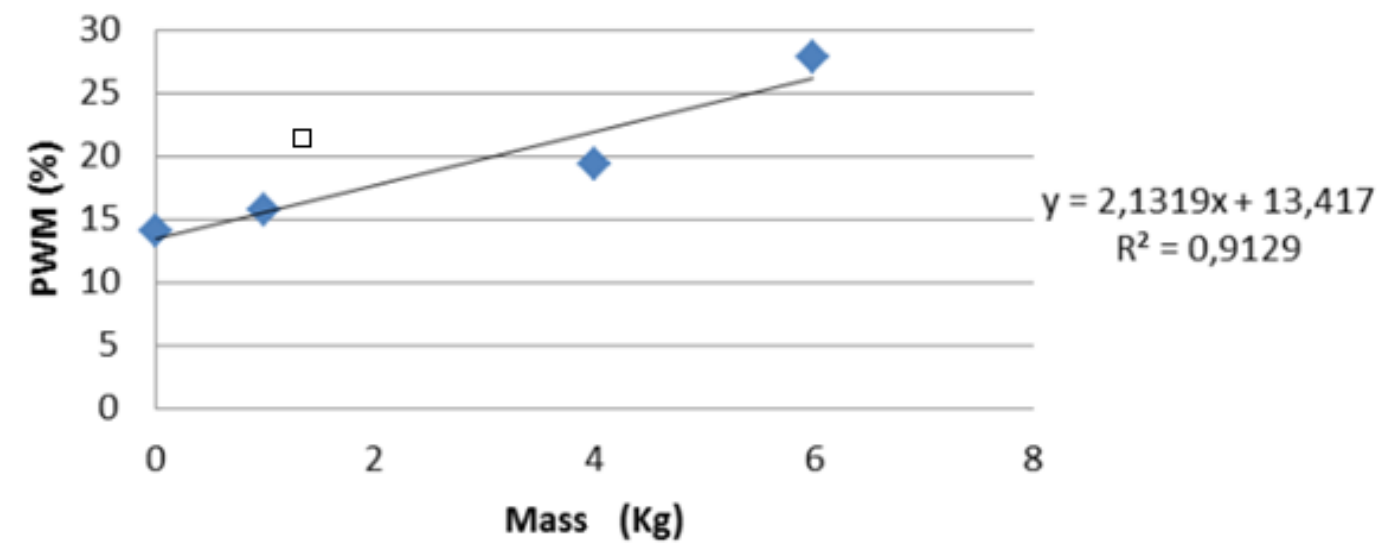

FIGURE 5. The Relationship between PWM and Mass at 100 RPM Setting Rotate Frequency.

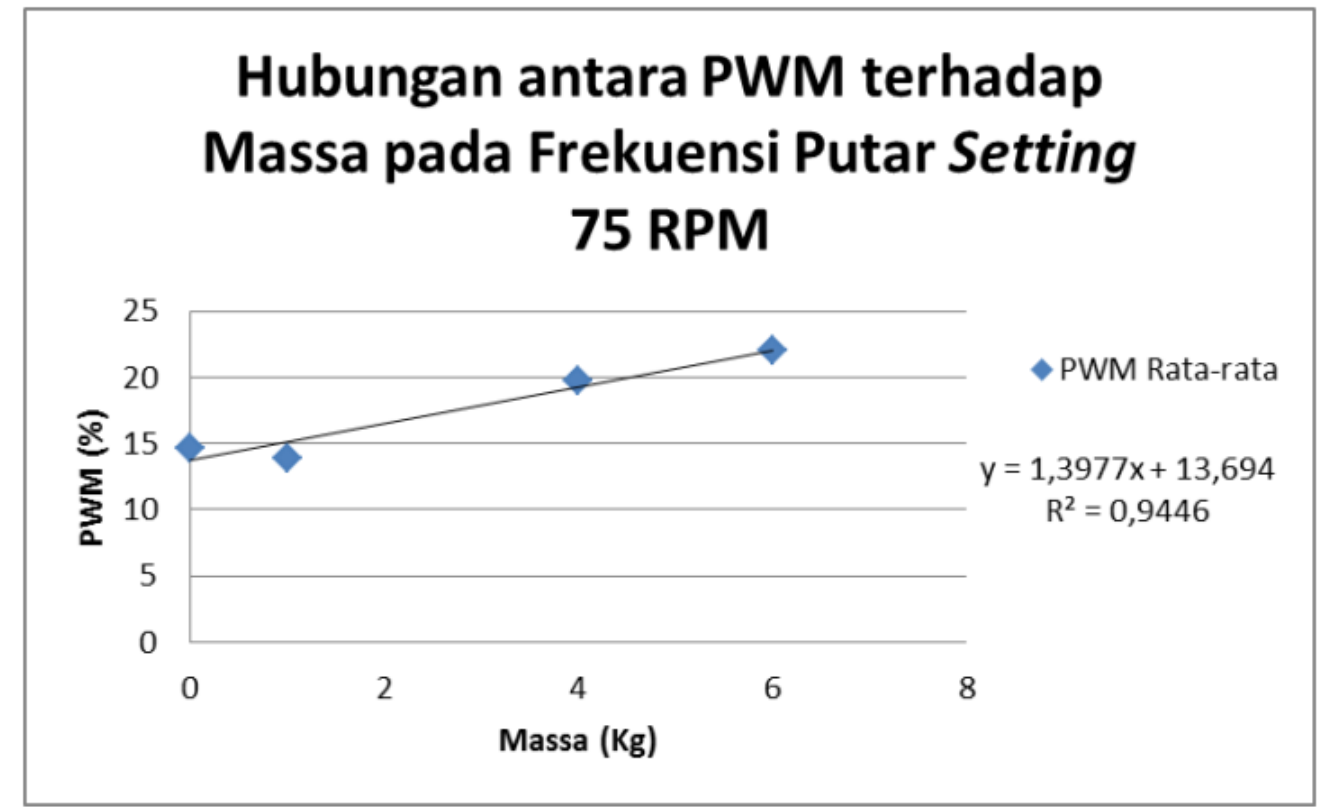

FIGURE 6. Graph of the Relationship between PWM and Mass at a Setting Frequency of 85 RPM.

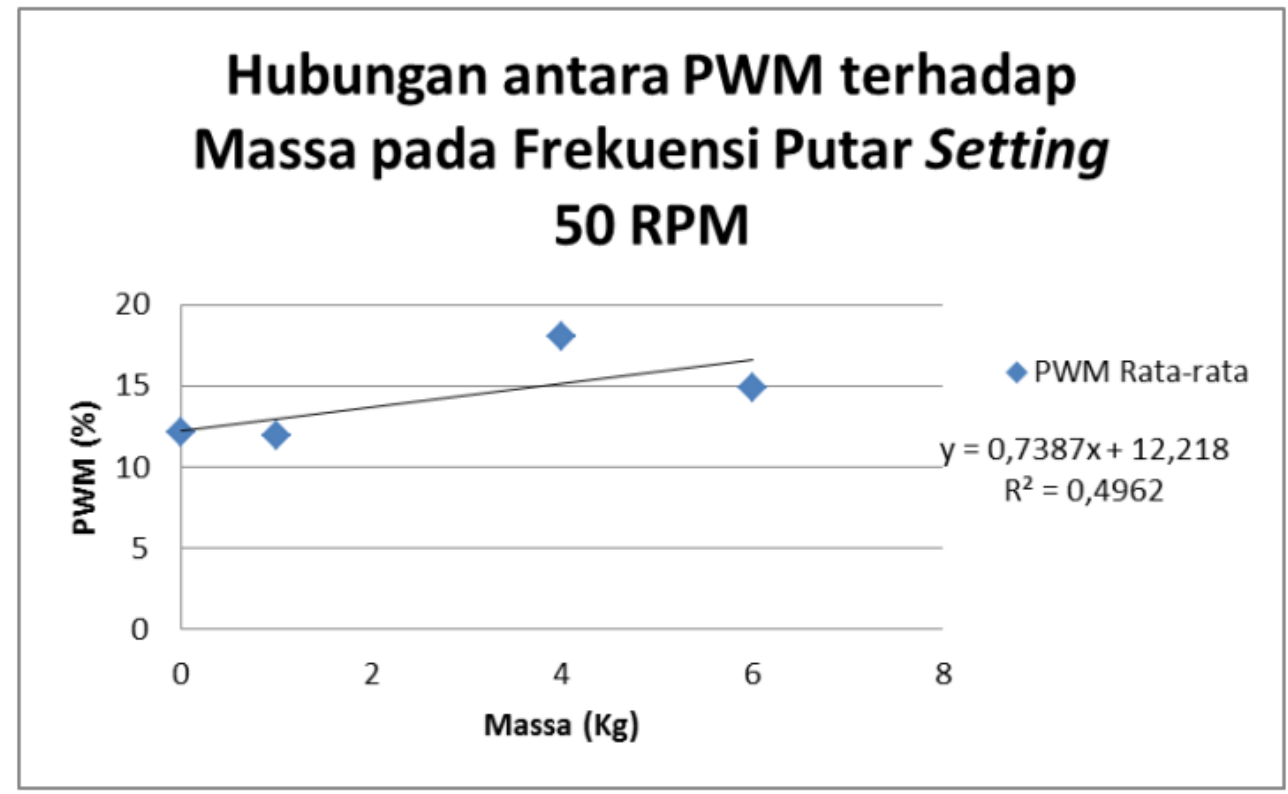

FIGURE 7. Graph of the Relationship between PWM and Mass at 70 RPM Setting Rotating Frequency. 
A constant decrease is shown on the graph, and a constant increase is the same as the graph, with the R2 value approaching the $\mathrm{R}=1$ value in Figure 5. It can be said that the sensor system made for each PWM has good linearity. It can be obtained that to produce the best rotary frequency control system; the best PWM linearity is used. It can be seen that the heavier the mass of the load given to the system, the lower the average rotating frequency produced.

Changes in the average PWM value are shown in Figures 5, 6, and 7. shows that the change in mass affects the mean value of the PWM. The more

the mass of the load is applied to the system. A not-too-significant increase is also shown by the value of R2 approaching one shown in Figures 5, 6, and 7. The equation for the percentage of instrument measurement error (\%) $=\Delta \mathrm{f} / \mathrm{f} \times 100 \%$. The results of the analysis of the percentage error of the motor rotational frequency are shown in Table

TABLE 2.. Relationship between PWM and Variation in Load Mass

\begin{tabular}{|c|c|c|c|}
\hline Massa & $\begin{array}{c}\text { f setting } \\
(\mathrm{RPM})\end{array}$ & $\operatorname{PWM}(\%)$ & $\Delta \mathrm{PWM}(\%)$ \\
\hline \multirow{3}{*}{4} & 100 & 19.38333 & 3.603631 \\
\cline { 2 - 4 } & 85 & 19.71667 & 3.042588 \\
\cline { 2 - 4 } & 70 & 18.06667 & 5.236335 \\
\hline \multirow{2}{*}{6} & 100 & 27.88333 & 2.591326 \\
\cline { 2 - 4 } & 85 & 22 & 1.55138 \\
\cline { 2 - 4 } & 70 & 14.9 & 4.324546 \\
\hline
\end{tabular}

Because the torque required by the system to maintain the regularity of the rotating frequency to remain at the set frequency value is more significant than others, the PWM changes in the system change according to the required torque. This result is why when the condition achieved is a low rotating frequency of $50 \mathrm{RPM}$ with an increased load mass of up to $6 \mathrm{Kg}$, the PWM only increases so that the resulting rotating frequency reaches the set frequency. After that, the PWM will adjust the torque needed to achieve the frequency condition according to the setting.

The change in the PWM value at the set frequency of 100 RPM that occurs is different from the previous condition, which continuously requires high torque at a low rotational frequency. In order to achieve steady-state conditions, a much higher rotational frequency is needed. Nevertheless, the increase in the average value of PWM occurs when the characteristics of the motor used are slightly less following the required conditions. This result is shown in the standard deviation value of the average PWM for $100 \mathrm{RPM}$ at the given load variation of $4 \mathrm{Kg}$ and $6 \mathrm{Kg}$ getting smaller because the PWM value decreases after the rotating frequency reaches the set frequency, then the PWM will increase. If this condition is used for a long time, it can cause damage to the motor due to heat and the hardware circuit used in the control system in this study. The PWM setting system with an average PWM error value in the first 60 seconds is indicated by a decrease in the error value, indicating the condition is presented in Table 1.

Based on Table 2, it can be seen that the variation of the load mass on the pedal when the system is working can affect the rotational frequency produced by the motor. This result is indicated by the change in the average rotating frequency taken every 60 seconds. The sampling is taken when the rotating frequency reaches the set frequency value.

\section{System Response Time Measurement}

One of the criteria for quality in the regulatory system is the response time of the tool. Response time is the ability of the tool to reach the setting. Therefore, the testing was carried out to determine the response time of the system that had been made. The system response time will be shown in Table 3. 
TABLE 3.. Relationship between Response Time at each Rotation Frequency to Variation of Load Mass.

\begin{tabular}{|c|c|c|}
\hline $\begin{array}{c}\text { Massa } \\
(\mathrm{Kg})\end{array}$ & $\begin{array}{c}\text { f setting } \\
(\mathrm{RPM})\end{array}$ & $\begin{array}{c}\text { Steady Time } \\
(\mathrm{s})\end{array}$ \\
\hline \multirow{4}{*}{4} & 70 & 5 \\
\cline { 2 - 3 } & 85 & 5 \\
\cline { 2 - 3 } & 100 & 5 \\
\hline \multirow{3}{*}{6} & 70 & 3 \\
\cline { 2 - 3 } & 85 & 5 \\
\cline { 2 - 3 } & 100 & 5 \\
\hline
\end{tabular}

Based on the data obtained, it appears that the value of the system response time increases when the load is added. The response time that occurs depends on the resulting PWM value; in other words, to reach the set frequency, the PWM will continue to increase starting from condition 0 until it reaches the setting rotation frequency condition. By increasing the required PWM value. Each response time resulting from different setting frequencies produces differences in each interval of increasing response time.

\section{CONCLUSION AND SUGGESTIONS}

From the research that has been done, it can be concluded that:

1. This motor rotational frequency regulation system uses a PID system with proportional, integral, and derivative constants in this system are $0.055,2.545,0.00005$. The error value $<5 \%$ indicates that the selected $\mathrm{Kp}, \mathrm{Ki}$, and Kd values are not following the expectations of the stability of the control system because it uses the trial and error method.

2. The average PWM value for each setting frequency increases with each given a heavier load variation. 3 . In this study, the response time values obtained for each increase in the load mass at each setting frequency increase. When the heaviest mass of $6 \mathrm{Kg}$ is applied, the response time for $70 \mathrm{RPM}$ is 3 seconds, $85 \mathrm{RPM}$ is 5 seconds, and 100 RPM is 5 seconds.

\section{REFERENCE}

1. Andrianto, H. 2008. Pemrograman Mikrokontroler AVR ATMega 16 Menggunakan Bahasa C. Yogyakarta: Andi Publisher.

2. Anonymous, $2006 . \quad$ Stroke http://www.americanheart.org.[Accessed American Heart Association.

3. Dalimin. 2006 Rancang Bangun Dan Proses Pembuatan Prosthesis PTB Supra Condylar Kanan Pada Amputasi Bawah Lutut, Poltekkes Surakarta Progam Studi Orthotik Prosthetik, Surakarta

4. Diserens, K., Perret, N., Chatelain, S., Bashir, S., Ruegg, D., Vuandens, P., Vingerhoets, F. 2007. The Effect of Repetitive Arm Cycling on Post Stroke Spasticity and Motor Control Repetitive Arm Cycling and Spasticity. Switzerland: Journal of the Neurological Sciences.

5. Doebelin, E.O. 1990. Measurement Systems Appilcation and Design, 4th Ed. McGraw-Hill Publishing Company. New York.

6. Dunn, PF. 2005. Measurement and Data Analysis for Engineering and Science. McGraw-Hill Publishing Company. Singapore

7. Gabriel, J.F. 1996. Fisika Kedokteran. EGJ : Jakarta.

8. Garison, Susan, J; 2001. Dasar-Dasar Terapi Dan Rehab Fisik, , Hipokrates, Jakarta

9. Ivey, F.M., Macko, H., Charlene, E., Richard, F. 2006. Exercise Rehabilitation After Stroke.NeuroRx: The Journal of the American Society for Experimental NeuroTherapeutics.

10. Johnstone, M. 1991. Therapy for Stroke. Singapore: Longman Group.

11. Kwakkel, G. 2007. Motor Rehabilitation Strategies After Stroke: What is the Evidence? Available from:

12. http://www.oandp.org/publications/jop/2007/2007-13.asp 2009]. 
13. Shephard, RJ., Bouhlel, E., Vandewale, H., Honod, H. 1987. Muscle Mass as a Factor Limiting Physical Work. Canada: Laboratoire de Physiologie du Travail.

14. Sutopo. 2001. Amputasi, Penataran Peningkatan Ketrampilan Tehnisi Orthotik Prostheti, RSOP RC Prof dr. R Soeharso, Surakarta

15. www.alldatasheet.com

16. Amarylis, S. 2010. Sistem Keran Wudhu Otomatis Berbasis Mikrokontroler ATMega8535 Dengan Solenoid Water Valve, Tugas Akhir, Jurusan Ilmu Komputer dan Elektronika FMIPA UGM, Yogyakarta.

17. Anonim, 2008, 16x2 Character datasheet/vishay/016m002b.pdf

LCD, http://www.datasheetcatalog.org/ 